\title{
Expert Innovators and Innovation Education: Mental Models in Practice
}

\section{Dr. Eden Fisher, Carnegie Mellon University}

Eden Fisher is Director of the Masters Program in Engineering \& Technology Innovation Management (E\&TIM) and Professor of the Practice at Carnegie Mellon University. She earned an A.B. in Chemistry from Princeton University and a Ph.D. in Engineering \& Public Policy from Carnegie Mellon University. Her experience includes over twenty years in industrial technology planning and innovation management.

\section{Dr. Indira Nair, Carnegie Mellon University}

Indira Nair retired from Carnegie Mellon University after 32 years. For the last 12 years there, she was the Vice Provost for Education and Professor in the Department of Engineering and Public Policy. She has designed and taught several interdisciplinary courses including ethics of science and technology, environmental science, technology and decision-making and radiation, health and policy. Her research has ranged over: risk assessment and communication, green design, bioelectromagnetics, education in general and pedagogies for the modern-day literacies such as scientific, environmental and global literacy.

Dr. Nair chaired the national Global Learning Leadership Council of the American Association of Colleges \& Universities (AAC\&U) from 2010 to 2013. She advises several universities and colleges on incorporating global and environmental literacy throughout the curriculum. She has served on numerous national committees including National Science Foundation's Committee on Equal Opportunities in Science and Engineering (CEOSE) and on the Division of Education and Human Resources Advisory Committee (EHR), the Educators Advisory Panel of the Government Accountability Office (GAO) and the Board of Student Pugwash USA. She has been involved in K-12 education and served as a member of the Board of the Pittsburgh Regional Center for Science Teachers, the School Reform Task Force of the Pittsburgh Public Schools, helping design the Science and Technology High School, the founding Boards of two charter schools -City High and the Environmental Charter School at Frick Park, and on the Winchester Thurston Advisory Board. She is co-author of a book, Journeys of Women in Science and Engineering: No Universal Constants, (Temple University Press, 1997).

She founded the Carnegie Mellon Chapter of Student Pugwash to encourage students to think about the social responsibility of science and technology. Her current quests and involvements include: a new scheme for general education including the new literacies; pedagogies for educating for innovation; increasing the inclusion of under-represented minorities across all segments of education; improving K-12 STEM education and bioelectromagnetics. She holds a Ph.D. in Physics from Northwestern University and a Pennsylvania teachers Certificate for high school science teaching

\section{Mr. Mustafa A Biviji, E2RG}

Mustafa A. Biviji has worked in different roles in the software industry, a policy think-tank and a consultancy firm. His interests lie in spotting and analyzing innovations in the electrical and electronics industry. Mr. Biviji is currently an Engineering Analyst at Energy \& Environmental Resources Group, LLC (E2RG). In this role, he analyzes new trends in the smart electric grid sector and consults with electric utilities to help adopt them. He has also developed a tool to determine new dynamic rates for utility customers on behalf of the U.S. Department of Energy. He has completed his M.S. degree in Engineering and Technology Innovation Management from Carnegie Mellon University, Pittsburgh, USA. Prior to which he had completed his Bachelor degree in Electronics Engineering from University of Mumbai, India. 


\section{Expert Innovators and Innovation Education: Mental Models in Practice}

Increasingly, one of the expectations for engineering education is to contribute to preparing students for leading innovation and creating new value. One particular challenge for educators is that successful innovations often build on years of experience. How can an academic program of limited duration effectively provide students with innovation education?

In this paper, we describe an approach to enhancing innovation education, building on insights of experienced innovators. In earlier work, an empirical model of the attributes of innovation - individual and organizational - was derived from interviews with experts in innovation. Here, the model was put into practice to inform and organize student observations in the classroom; it also had an important impact on teaching and assessment. Beyond the classroom, initial evidence from student internships suggests that this framework also was useful to these students as they transferred concepts to real world contexts.

While this paper describes one program, this approach could be a way to accelerate and deepen student understanding of the attributes and interactions that are characteristic of innovation.

Background and previous work

Our 2011 study engaged innovation experts to explore questions about the basic attributes of innovation and questions about how we can teach innovation: "Can innovation truly be taught in an intentional and systematic way? What content is important, and what approaches are helpful?" The study used a "mental models" approach, with open-ended interviews of a diverse set of innovation experts. ${ }^{1}$

The experts who contributed to the initial mental model of innovation emphasized that it takes years to achieve expertise: "You don't become an expert just the first time you play. You become an expert after years of playing and gaining that level of being able to assimilate chunks and things like that".

The mental models study of the expert innovators offers a framework for describing patterns in how innovators define and understand innovation. From the study, innovation is defined as: "A novel idea, put into practice, that offers value to customers and/or society." We represent the contributing elements identified by the innovation experts on a fishbone diagram that leads from motivating goals for innovation (customer or societal need or technical opportunity) to the innovation itself. Contributing elements for innovation are clustered as innovator skills and attributes, and processes and environments for innovation (Figure 1). Under each of these headings, each expert in the original study identified both promoters and inhibitors of innovation. 


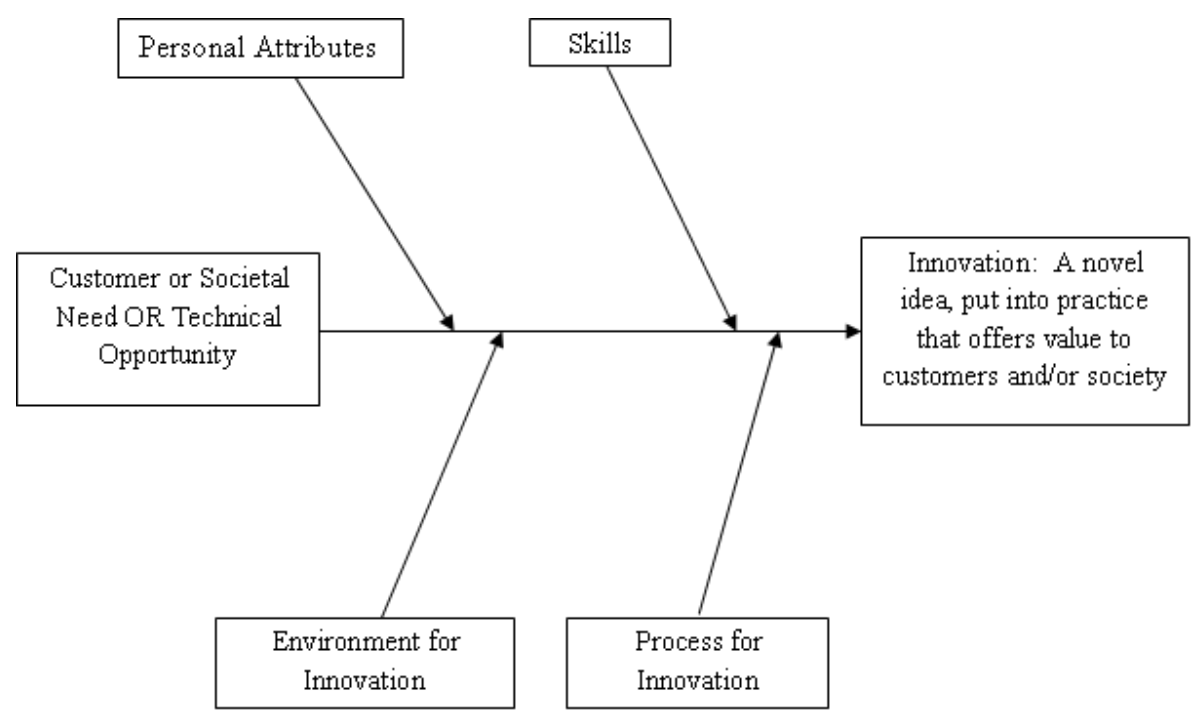

Figure 1: Framework for Organizing Mental Models of Contributors to Innovation ${ }^{1}$

We integrated this framework for innovation into the curriculum of our Engineering \& Technology Innovation Management masters program, specifically during a year-long seminar that includes expert innovators and innovation managers as guest lecturers. Students learn the framework as part of their introduction to their study of innovation, and refer to it as a touchstone throughout the program. A corresponding framework for innovation education has also been used to shape elements of the program itself. In a significant example, one expert innovator who guest lectures for the program drew upon the innovation framework to motivate a major shift in his approach to his class engagement. This use of the familiar framework provides a powerful way to discuss complex situations with the students.

Ultimately, the power of a framework is tested in the real world. Students in this program complete a required internship midway through their studies. When students report on these internships, the highlights and patterns from the mental models of innovation experts are now part of the way the students view and interpret experiences as they contribute to real organizations.

\section{Engineering and Technology Innovation Management in Practice}

Experienced innovators often provide guest lectures to students who are studying innovation. This widely used approach takes different forms and may address topics as diverse as the innovations and the guest innovators themselves.

The Engineering \& Technology Innovation Management masters program includes two semesters of seminars, organized and structured under the course title "Engineering and Technology Innovation Management in Practice." The opening lecture for this course introduces key concepts about technological innovation and innovation management. Students are introduced to a range of concepts that have been captured in the literature, 
including: models of innovation processes, ${ }^{2}$ roles in innovation, ${ }^{3}$ factors that influence creativity $^{4,5}$ and innovation skills that can be practiced. ${ }^{6}$

During the opening lecture, the students are also introduced to the mental models of innovation experts ${ }^{1}$ and the Framework for Organizing Mental Models of Contributors to Innovation from earlier work (Figure 1.) As they will be hearing from experts throughout the course, this framework is offered as a tool to help focus and organize listening, questioning and their written reflections on individual seminars. From an educational perspective, this "innovation fishbone" is a type of "advance organizer" to facilitate learning. ${ }^{7}$

Over the semester, a different innovation expert presents a seminar each week. Within the overall context of innovation management, the speakers each highlight a different topic-such as Product Management, Design Thinking, The Role of Intellectual Property, or Value Propositions and Idea Selling. Students are assigned to write reflections that include not only "who, what, and so what", but also identify promoters and inhibitors of innovation. This practice reinforces and parallels the insights offered by innovation experts in the mental models study.

For an end-of-first-semester project, small teams of students synthesize their learning from the different expert innovator seminars and from additional research, and present recommendations to enhance innovation management. These presentations are motivated by the HBR article "Moon Shots for Management" challenges for management" that are proposed to drive new levels of accomplishment; the challenges are based on a conference attended by leading management scholars and business leaders.

In their presentations, the students often use the "innovation fishbone" to bring together key innovation concepts from different sources. To illustrate, some examples related to different elements of the framework:

Personal Attributes such as 'Be okay with failure', and 'being comfortable with multiple perspectives' were key promoters of innovation identified by students. In contrast, cognitive inertia, complacency and risk aversion were presented as Personal Attributes that can inhibit innovation.

Concerning important Skills for innovation, students cited a speaker who emphasized, "You should be cataloguing and capturing expertise and ensuring we have adequate expertise in those fields where we have to make decisions". Soft skills were also highlighted, including management and leadership skills, developing strategy, the ability to make decisions with imperfect data, communication skills, and developing an understanding of the holistic approach.

The Process for Innovation was highlighted in different ways. One team suggested 'understanding the customer through the creation of a story'. This was related to different user personas and how the product fits the needs of these different personas; knowing 
your audience and their cultural values and norms helps design a product that will suit them. Another group stressed the application of a stage-gate system in innovation management.

Students also proposed enhancing the Environment for Innovation, bringing together observations from seminar speakers (e.g., "First, force them to sit together" from expert A), "moonshots" (e.g., "De-structuring organizations and eliminating the pathologies of formal hierarchy"), and recommendations from student research and experience (e.g. "Synchronize their KPIs" and "Increase Length of CEO Contract".)

The innovation fishbone can also be a starting point for building related concepts; some student presentations suggested links between the Environment for Innovation, the Process for Innovation and Personal Attributes and Skills. For example: "Create an open organization which fosters communication and understanding ... Mentor employees so there is a greater level of trust. Embrace failure and eliminate the stigma associated with it so that employees are willing to take more risks."

Revisiting a seminar by an expert innovator

Learning about innovation can be a lifelong course of study. Even innovation experts may choose to find opportunities to learn more about innovation, about innovation management and about innovation education. In a significant example, an expert innovator who guest lectures for the program studied the expert mental model conclusions and decided to change the focus and nature of his guest teaching about an important innovation, in order to test the impact of the change.

The expert innovator had been part of the original mental models study. He embraced the hypothesis that students who study the full set of elements of the framework that innovation expert practitioners describe may become effective contributors to innovation more quickly than those who do not have a framework to organize their learning and experiences. He reviewed Figure 1, and carefully considered the five branches of the experts' innovation model: triggers for the innovation, disposition of the contributors, skills of the contributors, processes for innovation and environment for innovation. Then, he set out to highlight each branch as he engaged students in (re)solving a problem that had been very real forty years earlier.

After the reframing, a session that had originally been a lecture about a historic engineering development became a quick re-enactment of a team innovation. With the expert innovator as the team leader, the team of students experienced the dynamics of exploring possibilities and identifying specific actions necessary for creating value from a technically challenging problem in the context of real world constraints. The innovation mental models framework helped balance the discussion across a range of significant issues, while the expert provided powerful scaffolding that enabled students to test ideas and (re)discover pivotal moves by the original innovation team. 
Post-class assessments were also restructured, to align with the revised approach and focus. These assessments captured rich reflections of a range of aspects of innovation, reflecting progress toward the goal of teaching "how to innovate" beyond "how this specific innovation happened."

The aluminum can recycling story and the innovation expert mental model framework

The historic engineering development that was the subject of this example was the extremely successful "cradle to cradle" aluminum can recycling system, which continues to sustainably create environmental, economic and social value all over the world.

In 2009 and 2010, the expert, who had led the initial recycling project team in the 1970's, presented the aluminum can recycling story to an interdisciplinary class of engineering students in the course "Innovation for Energy and the Environment." As follow up to the class, a quiz was given to test recollection of the "who, what, when, where, why and how" of the history of can recycling.

The aluminum can recycling story lecture was well received, and student performance on the quiz was good, but the expert was not satisfied that the class was serving the purpose of teaching students how to innovate, as the class was specifically offered to students in the Engineering \& Technology Innovation Management professional masters program. In 2011, in light of learning from the innovation expert interviews, the objective was to "teach how to innovate" by creating a session that would engage students in the recycling problem. The challenge was particularly great, because the class for the 2011 presentation was "Engineering and Technology Innovation Management in Practice" - a group of students with an especially diverse set of technical backgrounds, including a number of students with no obvious connection to materials science, chemistry or environmental science.

The idea was to "take them back" to the early 1970's and invite them to be part of his team, so that in less than two hours they would experience a reenactment of developing a significant innovation that had actually required two years from the original contributors.

To start class, the background and context of the original 1970'situation was quickly and memorably communicated. The aluminum can had rapidly gained market share in the packaging world because of a number of advantages - each of which was itself a successful innovation; these included cost-effective 2-piece aluminum can manufacturing, and consumer friendly easy-open ends on the cans. Subsequently, however, some state policy makers had decided that the (non rusting, non recyclable) can was undesirable roadside litter, and passed a law to "ban the can." In response, the aluminum company marketing department had declared that aluminum cans were recyclable, and had bought back a mountain of scrap cans to support this initiative.

The technical team (which suddenly included a class of 21 st century innovation management students hypothetically transported to the 1970's) was presented with the challenge of making can recycling really work. As the class began, there was known 
technology and equipment for recycling thick, bare aluminum --- but not cans (which were thin and coated.) An additional complication was that the company's main business was smelting primary aluminum, so there was not uniform organizational support for creating a stream of recycled metal from cans.

Students were each given cans and shredded cans, so they could see and feel the nature of the material. A tub of water represented a furnace of molten aluminum in miniature, so that the discussion of the challenge of aluminum cans that float (in contrast to thicker aluminum extrusions that sank) was clearly illustrated. Bits of floating material were added to the surface of the liquid in the miniature model of a "furnace", as a proxy for the extensive surface contamination that the original team encountered when cans were first added to the melting furnace.

Where to start with the innovation? It was up to the students to start. One asked: what were the problems? What was the material on the liquid's surface in the furnace? What would happen if....? They asked. What would happen if the cans were smashed to remove air; would they sink?

The expert from the original team encouraged all the questions, and all the suggestions of what to try. In most cases, he could describe the eventual outcome of a proposed approach (as the original team had tried many approaches during their work.) He also described the discipline they had followed of new experiments every week, simultaneously trying multiple approaches, and carefully using their limited authorization to try something 'crazy' (with up to $15 \%$ of project funds).

The students listened to each other, and built on ideas. The expert did a masterful job of highlighting challenges and encouraging his new team. Within the two-hour class time, the class identified successful breakthrough approaches to two of the major barriers encountered by the original team.

The students reported their learning after the dynamic class session. Comments linked to each element of the innovation fishbone, including:

Triggers for Innovation

- It is important to identify the problem exactly out of the whole host of issues.

- Because it is hard and expensive to separate aluminum from the bauxite ore to the desired aluminum alloy, there was a technical-economic opportunity to recycle cans back to cans of original composition of the same quality - if it could be cheaper than original can production.

- In the lecture there was definitely a need to get rid of used aluminum cans in society. They did not rust and degrade in nature, they remained in the environment and that upset a lot of people.

- It was interesting that the bold moves by the marketing team to buy back aluminum cans motivated the engineering team to innovate. It wasn't a matter of the likely benefit of if an innovation occurred, but rather what consequences would be faced if an innovation didn't occur. 
- Other needs/problems came up during the recycling process such as the need to get rid of the gas oxidizing reaction, clogging and floating problems.

Personal Attributes

- Don't be afraid to try out stupid things and sometimes it pushes you nearer the right solution quicker by doing that.

- Personally, I found my problem in this seminar. That is I am afraid to express my idea, even though it came up to be the right method. ... But there are two reasons why I didn't say it. First, it's because I failed to catch everyone's idea during the discussion. I was afraid that what I said is the same as what another said. The other reason is I don't know whether an appropriate pump is available ... which is also actually because I am afraid to speak a wrong answer.

Skills

- $\quad$ There were real technical aspects to the innovation behind solving this problem. Such as the pump aspect- the original pump would not work and was being corroded by the solution flowing through it. Therefore a different kind of pump was created that could produce high velocity without a lot of head.

- There was also a chemical component to the innovation. Knowing how to deal with the coating by pre-treating the cans before melting them (doing this at a different temperature) and understanding the oxidizing reaction that was going on.

- The leader was able to help everyone know the priorities. He also made sure that two people's ideas are connected.

- Innovation is not a single player game. People build on other people's thoughts. Formatting the team is what drives innovation.

- We have to think about all different stakeholders because they will either help or hinder innovation.

Process for Innovation

- It required prioritizing activities and then coming back to the process to solve a particular question.

- The innovation process is constant, continuous. We can find an opportunity, come up with an idea, but in order to refine it and have an original procedure, service or product we have to innovate by steps. The recycling process was not just the idea, but every stage had new challenges.

- In order to produce innovation you have to experiment and iterate fast.

- The use of parallel experimentation is a means of inspiring competition and "amplifying" efforts/results among team members.

- It is important to suggest ideas that I might not think are right. I had the idea of a pump, but I wrote it off as something that was not feasible right away. It turns out the pump would just need more innovations which other people could have provided. 
Environment for Innovation

- The leader of the team presented the needs and, with a dynamic of questions and answers, made us to share our thoughts and ideas of how to approach the challenges. Every idea was improving the final product either because it was connected with the previous one or because it was a different option to get the same goal.

- It is extremely important if everyone is given an equal opportunity for his or her ideas. It is also important that the ideas are connected looking at the uncertain future. A leader who understands the team composition, and dynamics that result from the team is essential. A team with a combination of core specific background along with some creative thinking was necessary for the solution to be formed.

- What really interested me here was the observation that not all engineering endeavors and inventions are financially sound decisions to make. However, operations and marketing allowed for $15 \%$ of the decisions to be poor financial ones, taking down the barriers that large organizations can put upon the innovation process.

\section{Overall}

- Almost any problem can be solved through a systematic approach to innovating in order to overcome them. The two biggest drivers are finding a need or problem to solve, and then determining what the main cause of that problem might be. A well-designed team, with the proper resources can then start dissecting the problem and better understanding its causes. Most of all, it's important to come up with as many potential solutions to evaluate and consider as a team. As we were told, "speak before you think."

- Successful innovation has a value component to it, ... in order to be adopted.

- The implementation of this process has generated a reduction in energy consumption and in greenhouse gases emissions as well as saving of landfill space, so it is not only the economic value that was created, but also environmental positive impact.

- Although people are naturally afraid of losing and the unpredictability of change, there are others in organizations that can inspire those who are afraid to take a chance and foster innovation.

This class was designed and conducted by an expert who had "been there" and could walk the students through the experience. He elicited their strong participation in the process of reenacting the project choices and provided immediate feedback on ideas -producing strong learning.

The PhD student teaching assistant described this as a "choose your own adventure" class. It provided experience that students would not have had access to without the direct participation of the expert. 
The innovation mental models framework helped the expert and the students more explicitly consider all aspects of the innovation, enriching both the class and student reflections.

Expert mental models and student internships

The ultimate test of innovation education occurs when students engage with the real world. As a program requirement, every student in the Engineering \& Technology Innovation Management masters program completes a summer internship midway through his or her studies. The positioning is such that students can both prepare for, and learn from, their experiences. Although each internship is unique, every student experiences being part of the innovation ecosystem in an organization that is leveraging technology to create value.

For the student cohorts whose pre-internship preparation included the expert mental models framework, their post-internship reports and presentations included important observations and contributions concerning every branch of the innovation fishbone.

The motivation and triggers for promising innovation is affected by the context; one student who interned in the developing world highlighted the difference in innovation opportunities associated with the "bottom of the pyramid" vs. first world perspectives.

In considering Personal Attributes contributing to successful innovation management, one student admired the "zest in interactions with customers" he observed from a supervisor. Other students were more self-reflective: considering which personal attributes helped them contribute to innovation, and which were inhibitors. Growing confidence was cited as a positive contributor.

When students identified Skills they each had developed and used to contribute to innovation during internships, the set reflected the diversity of the students and their internship experiences. A range of technical and innovation management skills were highlighted. Examples of more technical skills included: understanding of motors for promoting a startup company's novel offering, fundamental materials science contributions towards a patent application in pharmaceutical formulation, and agile software development for a Silicon Valley firm. Innovation management skills often complemented technical skills, from using concepts of appropriability and complementary assets in building strategy for a startup company, to integrating rapid forecasting of budgets into an engineering firm's sales process, to designing a process to incorporate sustainability into product development for a large corporation. Additional skills development reported included leading a biomedical products group in "Questionstorming" and learning to communicate concepts with drawings in a design firm.

The extent to which a Process for Innovation should be specified and managed was one of the questions raised in the original interviews with experts. ${ }^{1}$ In their internship experiences, students encountered this tension. However, because Process for Innovation 
is explicitly highlighted in the mental models framework, students are more conscious of processes and patterns. A student who was involved with biomechanical research observed:

When tackling with problems in research, usually you cannot find an existing answer. They are heuristic. But there is a fixed pattern to figure out heuristic problems. The methodology is as follows:

1. Analyze the problem and divide the task into subtasks, each subtask should be featured with independent background. Note that this is not dividing the task such that the resulting subtasks could be handled at the same time. To divide problem this way is because each subtask need different preparation. And it is more efficient to work on jobs in the same subtask in a row.

2. For each task in specific background, do research on other researchers' solution, related field knowledge. Typically, one would search the most recent literatures to find what he needs. List the possible solutions.

3. For each solution one could find, do feasibility analysis. The feasibility analysis includes the time cost, namely the learning curve of the new knowledge needed, difference in application environment, potential risk, accessibility to support and the money cost. Select the most promising method and apply it for your purpose.

4. If this method fails, try another method. Otherwise move on to next subtask.

This is the typical working model for all researchers and is exactly what I did to complete my work. And the most crucial part of this methodology is the feasibility analysis for potential solution. The analysis may vary for different kind of task. The smooth progress of the procedure needs rich experience in this analysis.

Because of the range of internship situations, interns reported a wide range of observations associated with Environment for Innovation. Elements of work culture were very different at an energy startup vs. an established utility vs. a large firm that provides software as a service; the ease of communicating ideas and deploying decisions was affected by these differences in environment.

\section{Conclusion}

The students returning from their internships were already focused on how they hoped to direct their future engagement as practitioners in the innovation ecosystem. If each student brings the expert innovator mental models framework as a lens for shaping and reflecting on their work, it offers him or her a conceptual scaffolding that becomes increasingly refined with experiences. This can continue to shape and advance their innovation education throughout their careers.

Engineering innovation education is an opportunity that invites exploration of new approaches to teaching. Initial results from the application of expert mental models of innovation to education offer promise. This can be a powerful way to integrate expertise into innovation education. 
The education literature concerning "meaningful learning" also offers insights for engineering innovation education and encourages engaging both teachers and students. For example, Novak's articulation of "construction and reconstruction of meanings" and "meaningful learning and new knowledge construction" describes the importance of "well organized relevant knowledge structure and high commitment to seek relationships between new and existing concepts and propositions".

Further work to explore how this type of learning applies to innovation can lead to more robust results and pedagogies to enhance innovation education. Because of the nature of innovation, expert mental models are valuable inputs for this exploration.

1. Fisher, E., Biviji, M. and Nair, I., "New Perspectives on Teaching Innovation to Engineers: An Exploration of Mental Models of Innovation Experts Proceedings of the 2011 ASEE Annual Conference and Exposition, Vancouver, BC, June 2011.

2. Kline, S. J. and Rosenberg, N., “An Overview of Innovation”, in The Positive Sum Strategy: Harnessing Technology for Economic Growth, R. Landau and N. Rosenberg, eds., National Academy Press, 1986.

3. Kelley, T. and Littman, J., The Ten Faces of Innovation, 2006.

4. Amabile, T. M., "How to Kill Creativity", Harvard Business Review, September-October 1998.

5. Breen, B., "6 Myths of Creativity", Fast Company, December 2004.

6. Dyer, J. H., Gregersen, H. B. and Christensen, C. M., "The Innovator's DNA", Harvard Business Review, December 2009.

7. Ausubel, D. P., "The Use of Advance Organizers in the Learning and Retention of Meaningful Verbal Material", Journal of Educational Psychology, Vol. 52, No. 5., pp. 267-272, 1960.

8. Hamel, G., "Moonshots for Management", Harvard Business Review, February 2009.

9. Novak, J. D., "Meaningful Learning: The Essential Factor for Conceptual Change in Limited or Inappropriate Propositional Hierarchies Leading to Empowerment of Learners", Science Education, Vol. 86, Issue 4, pp. 548-571, July 2002. 